\title{
Renal Cation Excretion in the Hypocalcemic Premature Human Neonate
}

\author{
DAVID R. BROWN ${ }^{(24)}$ AND BETTY H. STERANKA \\ The Department of Pediatrics, Magee-Womens Hospital. University of Pittsburgh School of Medicine, \\ Pittsburgh. Pennsylvania. USA
}

\begin{abstract}
Summary
We describe the interrelationship of the urinary excretion of sodium, calcium, magnesium, and phosphorus in 22 hypocalcemic premature neonates whose mean gestational age was 31.7 wk. Strong relationships between sodium excretion and calcium excretion $(r=0.85)$, sodium excretion and magnesium excretion $(r=$ $0.76)$, sodium excretion and phosphorus excretion $(r=0.61)$, and calcium excretion and magnesium excretion $(r=0.94)$ were demonstrated. Sodium intake during the 84-hr study period ranged from 2.9 to $34.5 \mathrm{mEq} / \mathrm{kg}$ and calcium intake during the same period ranged from 0 to $152.3 \mathrm{mg}$ of elemental calcium per $\mathrm{kg}$. The intakes of the other cations were negligible. All variables but phosphorus excretion $(r=-0.55)$ were independent of calcium intake whereas sodium excretion $(r=0.76)$, calcium excretion $(r$ $=0.72$ ) magnesium excretion $(r=0.62)$, and phosphorus excretion $(r=0.53)$ were all correlated with sodium intake. Serum calcium concentration at the end of the study was unrelated to total calcium intake during the 84 -hr study period, whereas it was negatively related to total sodium intake $(r=-0.71)$.
\end{abstract}

\section{Speculation}

We suggest that sodium intake and sodium excretion exert significant control over the excretion of calcium, magnesium, and phosphorus in sick, hypocalcemic, premature neonates. High sodium intake in this group of patients is associated with a lowered serum calcium concentration; thus, increased sodium intake and perhaps increased calcium excretion may play a role in the development or exacerbation of early onset neonatal hypocalcemia.

Studies of renal function in the premature neonate have demonstrated a very low glomerular filtration rate $(3,10,13,17)$ and inefficient tubular function exemplified by sodium wasting $(7,14$, 17). Renal sodium wasting by the premature neonate raises the possibility that other important cations may also be poorly conserved. Data from studies of human adults show that tubular handling of sodium, calcium, magnesium, and phosphorus are closely related to each other and that excessive excretion of one is accompanied by excessive excretion of all the others $(9,12,15)$. Similar data on the human neonate are not currently available.

The present study evaluates the interrelationships in the renal handling of sodium, calcium, magnesium, and phosphorus by the hypocalcemic premature neonate. In addition, the urinary excretion of these cations is examined in relation to the parenteral intake and estimated oral absorption of sodium and calcium. Finally the influence of the intake and excretion of sodium and calcium on serum calcium concentration is described. The possible importance of these interrelationships in the etiology of early onset neonatal hypocalcemia is discussed.

\section{MATERIALS AND METHODS}

The study population consisted of 22 male neonates admitted to the Neonatal Intensive Care Unit of the Magee-Womens Hospital between November 1976 and July 1978. These patients were part of a larger study of 50 neonates with hypocalcemia who participated in a prospective study of the use of parenteral calcium in the treatment of early onset neonatal hypocalcemia (5). Hypocalcemia was defined as a serum calcium $<7.0 \mathrm{mg} / \mathrm{dl}$ determined by atomic absorption spectrometry (21) or a serum-ionized calcium $<3.5 \mathrm{mg} / \mathrm{dl}$ determined by a calcium-selective immersion electrode (Applied Medical Technology Electrion) (18, 19). The 22 patients were randomly assigned to one of five treatment conditions. They received parenterally administered calcium gluconate as either a high dose (54 mg of elemental calcium per $\mathrm{kg}$ for $24 \mathrm{hr}$ followed by $27 \mathrm{mg} / \mathrm{kg}$ for the next $24 \mathrm{hr}$ ) by continuous infusion $(N=4)$ or in four divided doses per day $(N=4)$ or a low dose (18 $\mathrm{mg}$ of elemental calcium per $\mathrm{kg}$ for $24 \mathrm{hr}$ followed by 9 $\mathrm{mg} / \mathrm{kg}$ for the next $24 \mathrm{hr})$ continuously $(N=5)$ or in four divided doses per day $(N=4)$, or they received no parenteral calcium $(N$ $=5$ ). Calcium given by bolus infusion was injected over 60 to 120 sec. All patients were studied for $72 \mathrm{hr}$, and no patient received parenteral calcium on the third day. Blood samples were drawn from the patients at the time of entry into the study and at 24,48 , and $72 \mathrm{hr}$ after the start of calcium therapy.

The patients had urine collected continuously from I to $3 \mathrm{hr}$ before to $72 \mathrm{hr}$ after the parenteral calcium treatment was started. Each urine specimen was timed, measured, and frozen shortly after it was voided. Separate voidings were then combined into approximate 12-hr specimens, and an aliquot was refrozen for future laboratory testing. Partial or complete losses were noted, and these losses were accounted for in subsequent laboratory measurements and calculations. Measurements on each urine specimen included calcium, magnesium, phosphorus (22), and sodium (11). Except as noted above, clinical management and laboratory studies on which clinical management was based were not prescribed. Careful clinical records are kept on all patients admitted to the Intensive Care Nursery, and these were used as the source of fluid, calcium, and sodium intakes. Calcium intake was the sum of parenteral intake plus $50 \%$ of oral intake. Sodium intake was the sum of oral intake plus parenteral intake. The $50 \%$ absorption estimate for calcium is based on published work (6). We are unaware of a study of sodium absorption in a population of premature neonates, and we arbitrarily assumed 100\% absorption. Parenteral intake was the sum of intake via continuous infusion plus the amount received from the bolus injections used to clear umbilical arterial catheters. The amount of sodium received from these bolus injections was estimated to be $1 / 3 \mathrm{mEq}$ for each sample of blood drawn for laboratory measurement because the catheters were flushed with 2 to $2.5 \mathrm{ml}$ of normal saline each time a blood sample was drawn. Fluid intake was the sum of parenteral plus oral intake. Concentrations supplied by the formula manufacturer were used in calculating oral sodium and calcium intakes from formula feedings.

Data were evaluated statistically using the Pearson product moment correlation coefficient (16). Parental informed consent was obtained prior to enrolling a patient in the study.

\section{RESULTS}

The 22 patients ranged in gestational age from 28 to $36 \mathrm{wk}$ with a mean gestational age of $31.7 \mathrm{wk}$. Gestational age was calculated 
from the first day of the last normal menstrual period and was confirmed by physical examination using a modified Dubowitz technique (4). When an accurate menstrual history was not available, results of the physical examination alone were used to define gestational age. Birthweight ranged from 1.1 to $2.5 \mathrm{~kg}$ with a mean of $1.7 \mathrm{~kg}$. Apgar scores at one min ranged from 3 to 8 (mean $=$ $5.6)$ and at 5 min ranged from 4 to $9($ mean $=7.1)$. In addition to having hypocalcemia, the patients had a number of other serious medical problems. Nineteen $(86 \%)$ had hyaline membrane disease, $13(59 \%)$ had a mean arterial blood pressure of $\leq 30$ torr during the first $12 \mathrm{hr}$ of the study, eight (36\%) had seizures, five $(23 \%)$ had a pneumothorax, and five $(23 \%)$ died. Seventeen patients had their urine checked for the presence of blood and protein. At the start of the study, 10 had hematuria and 16 had proteinuria; at the end of the study, six had hematuria and 12 had proteinuria.

The relationship of sodium excretion to the excretion of calcium, magnesium, and phosphorus is presented in Figure 1. The amounts excreted are totals over the 84 -hr study period which includes extrapolated values for the $12 \mathrm{hr}$ before the beginning of calcium

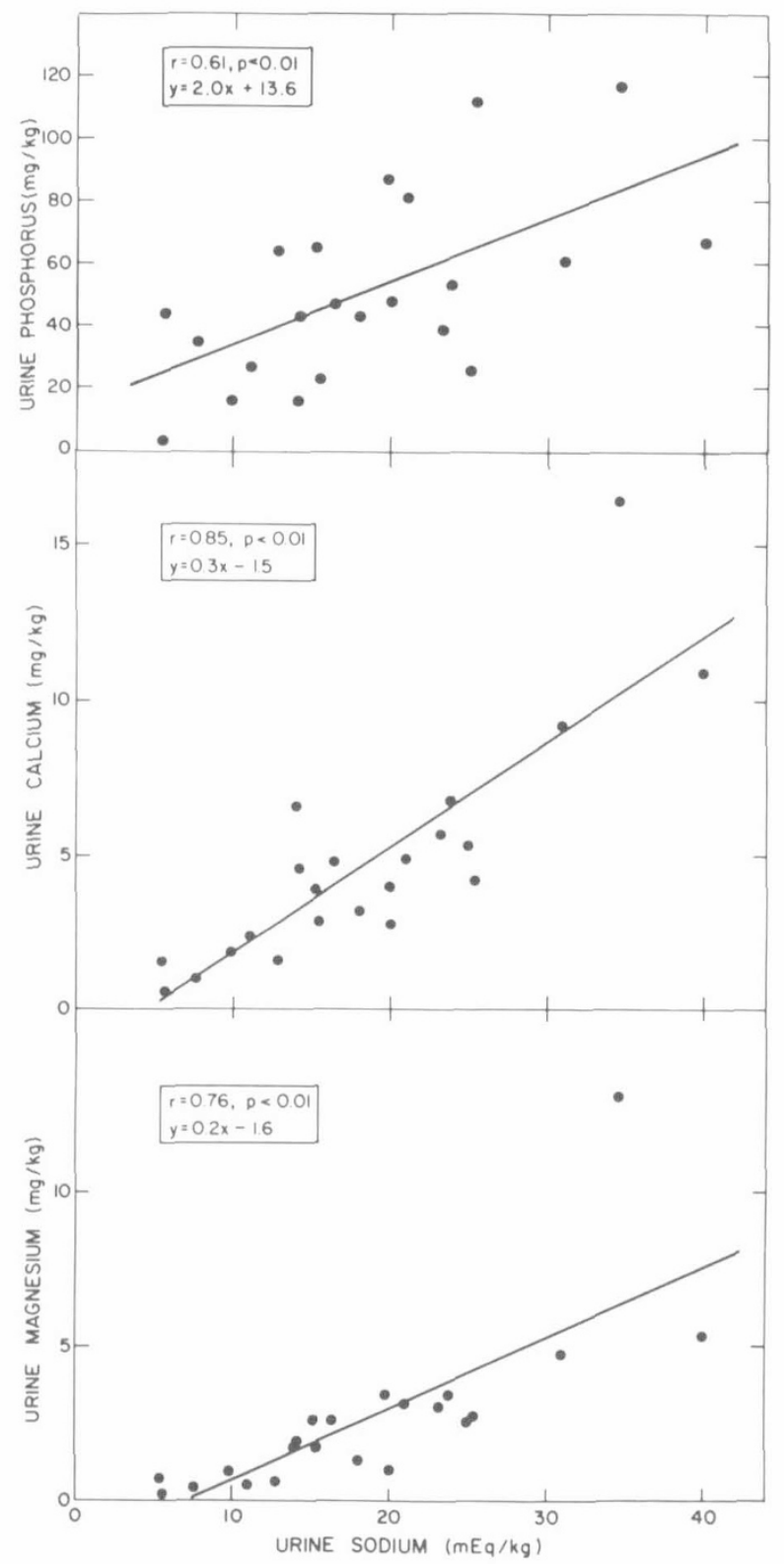

Fig. I. Correlational relationship of sodium excretion to magnesium, calcium, and phosphorus excretion. Inset in each scatter plot contains the Pearson product-moment correlation coefficient $(r)$, the $P$ value, and the equation for the regression line which is drawn on each scatter plot. The numerical values represent amounts excreted during the entire 84 -hr study period (see text for details). therapy. This extrapolation is based on the amount actually excreted before the start of therapy. The mean amounts of sodium, calcium, magnesium, and phosphorus excretion during the 84-hr study period were $18.6 \mathrm{mEq} / \mathrm{kg}, 4.8 \mathrm{mg} / \mathrm{kg}, 2.6 \mathrm{mg} / \mathrm{kg}$, and 50.9 $\mathrm{mg} / \mathrm{kg}$, respectively. Sodium excretion and calcium excretion were highly correlated $(r=0.8471 ; P<0.01)$ so that over $70 \%$ of the variance in calcium excretion could be accounted for by knowing the sodium excretion. The relation of sodium excretion to magnesium excretion $(r=0.7569 ; P<0.01)$ was almost as strong; over $55 \%$ of the magnesium excretion variance could be predicted from the sodium excretion. A slightly weaker relationship was present for phosphorus excretion $(r=0.6119 ; P<0.01)$. The results shown in Figure 2 follow from those in Figure 1. Magnesium and calcium excretions were so strongly related $(r=0.9376 ; P<0.01)$ that more than $85 \%$ of the variance in one could be predicted from knowing the other, and magnesium and phosphorus excretions were also positively related $(r=0.6588 ; P<0.01$; Fig. 2$)$. Phosphorus excretion was unrelated to calcium excretion $(r=0.2801$ with the elimination of the one outlying point).

Sodium and calcium intakes were analyzed to determine their relationship to the urine content of sodium, calcium, magnesium, and phosphorus. Sodium intake during the 84-hr study period ranged from 2.9 to $34.5 \mathrm{mEq} / \mathrm{kg}$ with a mean intake of $13.9 \mathrm{mEq} /$ $\mathrm{kg}$ for the 22 patients. Sodium excretion was the strongest correlate of sodium intake ( $r=0.7570 ; P<0.01$; Fig. 3 ) where $57 \%$ of the variance in one variable could be predicted from the other. Other variables that were statistically significantly related to sodium

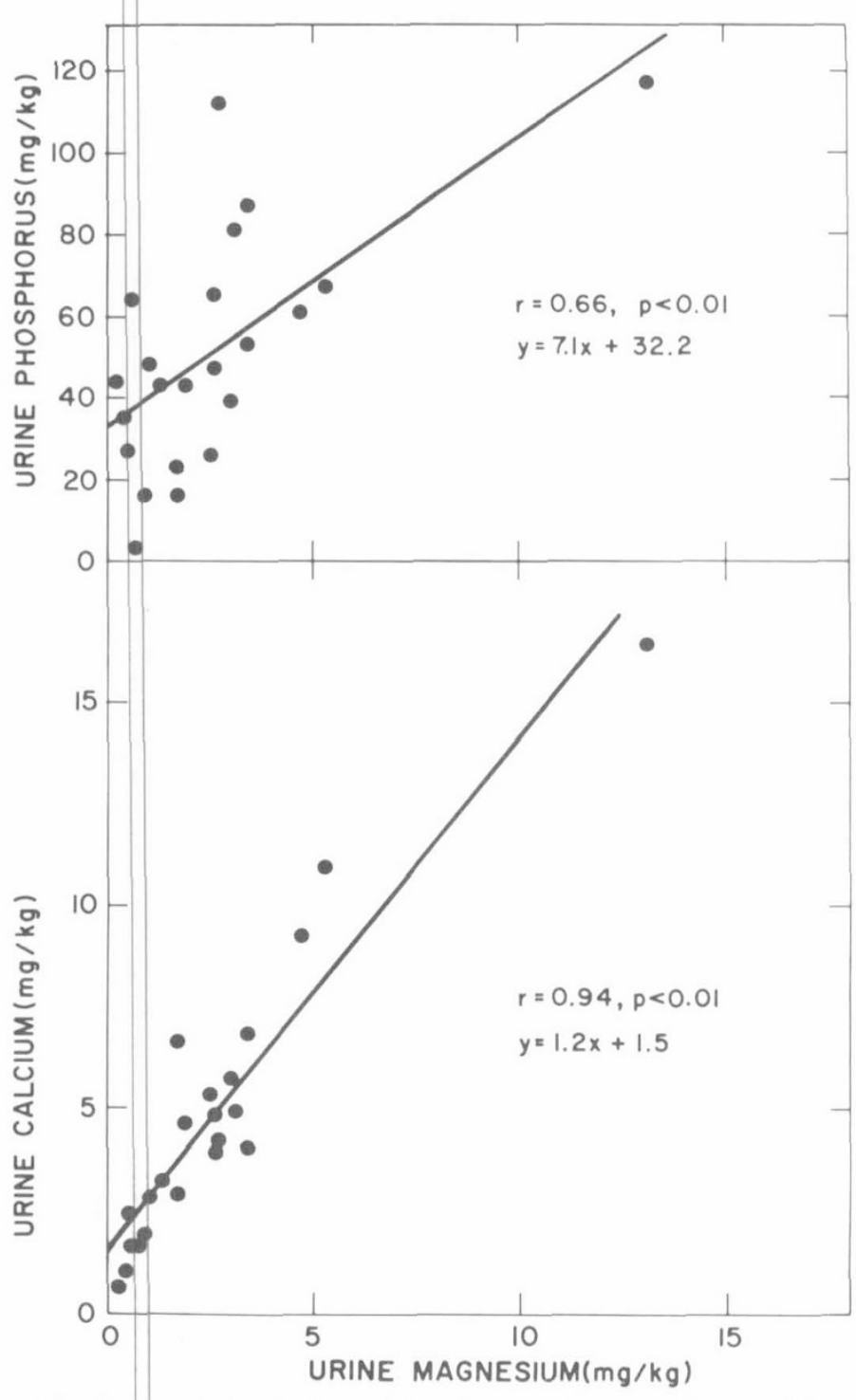

Fig. 2. Correlational relationships of magnesium excretion to calcium and phosphorus excretion. See the legend of Figure 1 for details. 

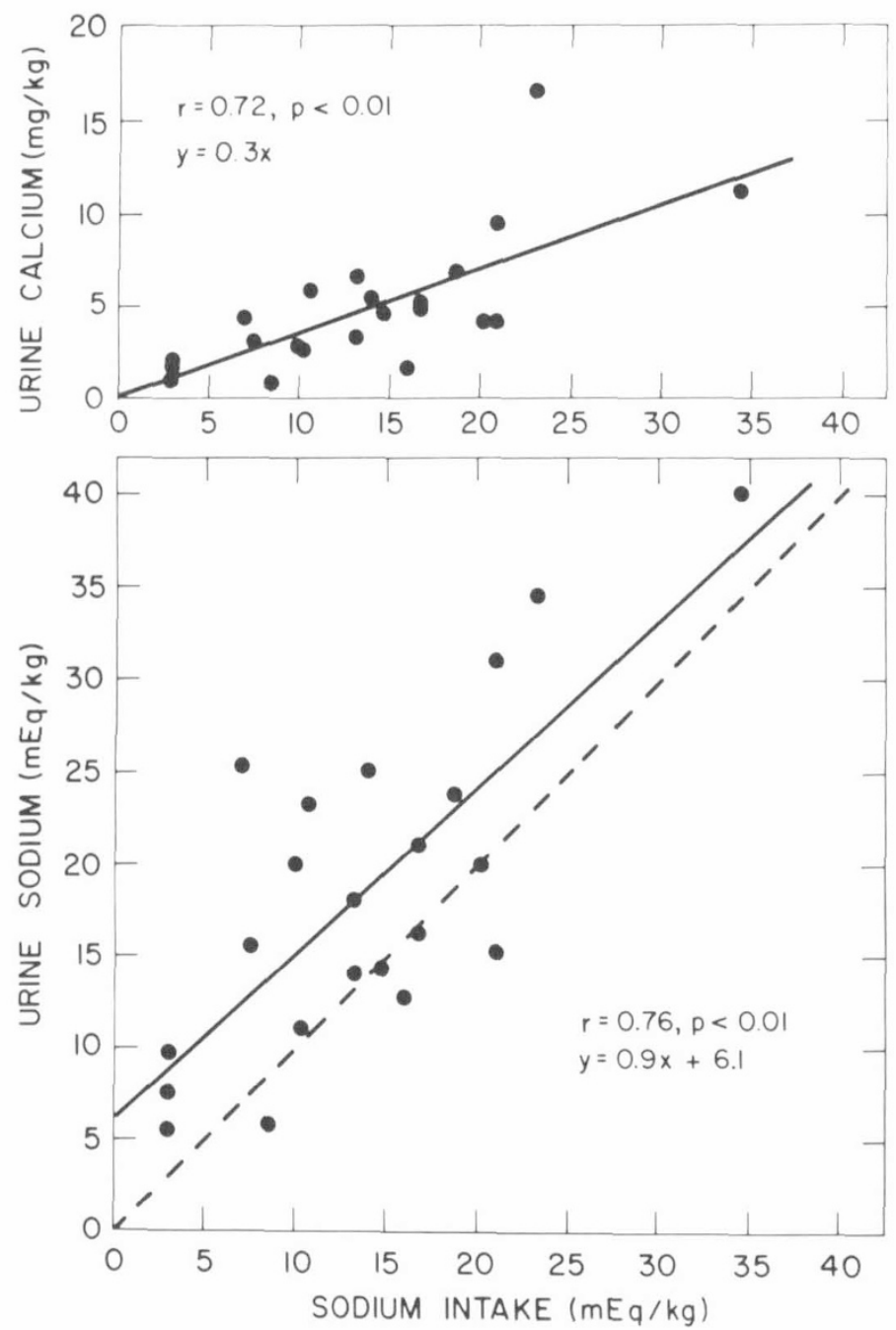

Fig. 3. Correlational relationship of sodium intake to sodium and calcium excretions. See the legend of Figure 1 for details. The broken line in the scatter plot of sodium excretion is the line of identity. Points above and to the left of the line represent examples of negative sodium balance.

intake were calcium excretion $(r=0.7191 ; P<0.01$; Fig. 3$)$, magnesium excretion $(r=0.6187 ; P<0.01)$, and phosphorus excretion $(r=0.5252 ; P<0.05)$. Calcium intake during the study period ranged from 0 to $152.3 \mathrm{mg}$ of elemental calcium per $\mathrm{kg}$ with a mean intake of $51.5 \mathrm{mg} / \mathrm{kg}$. Sodium and fluid intake and the excretion of sodium, calcium, magnesium, and water were all independent of calcium intake. Only phosphorus excretion was significantly correlated with calcium intake $(r=-0.5536 ; P<$ $0.01)$. Although the estimates of oral intake (i.e., absorption) used by us are only rough approximations, they are in fact of no practical consequence to the correlational relationships involving intake because the amount of oral intake represented only a small fraction of the total intake. We evaluated all these relationships using only parenteral intake, and the correlation coefficients changed very little, and the statistical significance of the correlation coefficients did not change at all.

A negative relationship was found between birthweight and sodium excretion $(r=-0.4759 ; P<0.05)$ although none could be demonstrated between gestational age and sodium excretion. In addition, the mean tubular reabsorption of sodium, 1-[(serum creatinine) (urine sodium)/(urine creatinine) (serum sodium)], was 0.951 and was weakly correlated with gestational age $(r=0.4293$; $P<0.05)$ and birthweight $(r=0.5288 ; P<0.01)$.

Fluid intake during the study ( $84 \mathrm{hr}$ ) ranged from 231 to 442 $\mathrm{ml} / \mathrm{kg}($ mean $=324 \mathrm{ml} / \mathrm{kg})$ and was weakly correlated with fluid excretion $(r=0.4817$; $P<0.05)$ which ranged from 130 to 393 $\mathrm{ml} / \mathrm{kg}($ mean $=259 \mathrm{ml} / \mathrm{kg})$. Fluid intake was unrelated to any of the other variables studied, but fluid excretion was correlated with sodium excretion $(r=0.6921 ; P<0.01)$, calcium excretion $(r=$ $0.5717: P<0.01)$, and magnesium excretions $(r=0.4352 ; P<$ $0.05)$.

Because of the relationship of sodium intake to the excretion of calcium and the lack of relationship of any urinary cation to calcium intake, the relationship of calcium intake and sodium intake to final serum calcium concentration was evaluated. At the end of the study, $72 \mathrm{hr}$ after parenteral calcium was first given, serum calcium concentrations ranged from 5.3 to $10.9 \mathrm{mg} / \mathrm{dl}$. At that time. $14 \%$ of these patients (three of 22) still had serum calcium concentrations of $<7.0 \mathrm{mg} / \mathrm{dl}$. Figure 4 shows the relationship of both total sodium intake and total calcium intake during the 84 -hr study period to the serum calcium concentration at the end of the study. There was no relationship between calcium intake during the prior 3.5 days and serum calcium concentration; whereas there was a moderately strong negative relationship between sodium intake and serum calcium concentration $(r=$ $-0.7092 ; P<0.01)$. As summarized in Figure 5, there were also significant negative relationships between the final serum calcium concentration and the excretion of sodium $(r=-0.4811 ; P<0.05)$ and the excretion of calcium $(r=-0.5175 ; P<0.05)$.
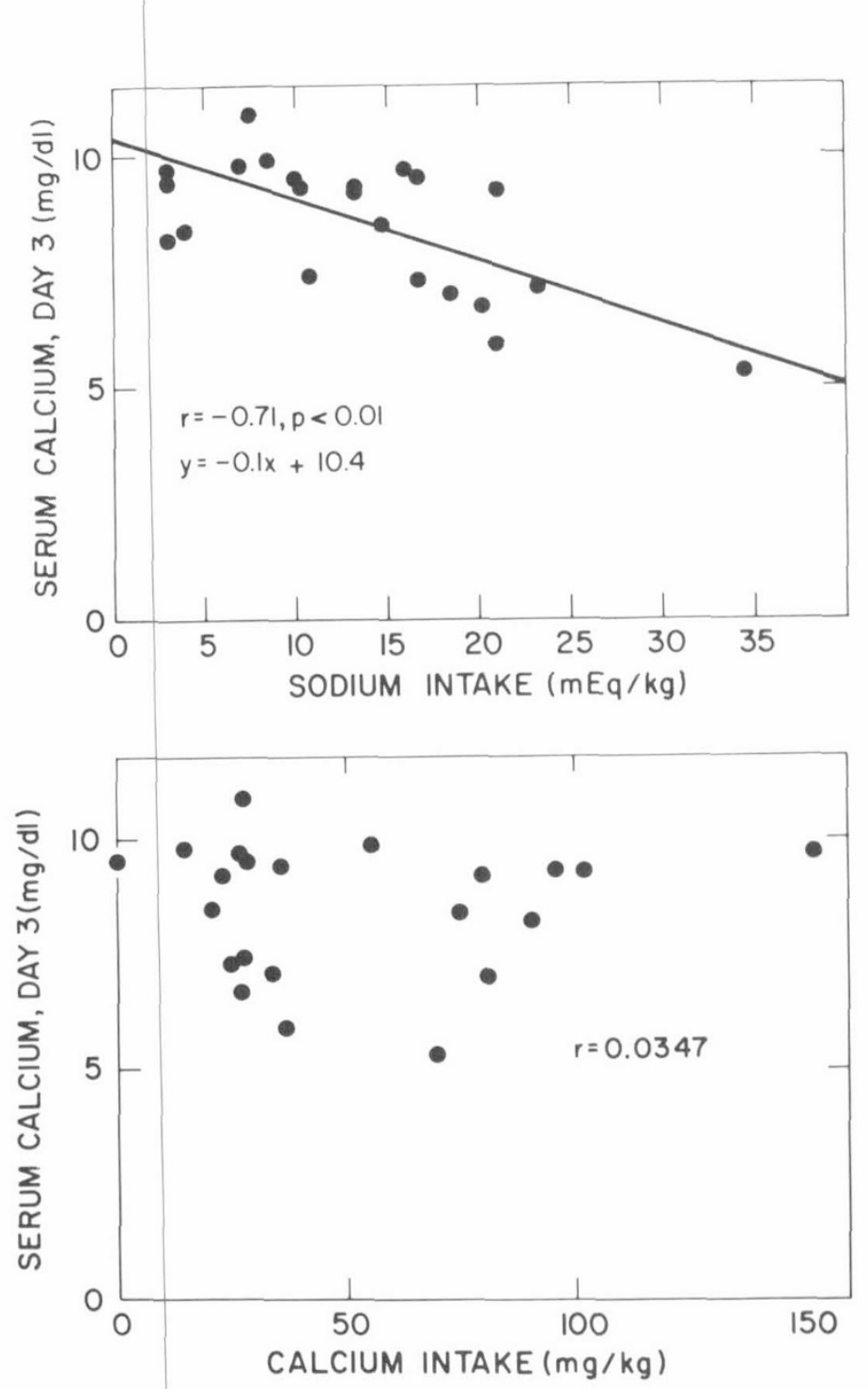

Fig. 4. Correlational relationship of serum calcium concentration at the end of the study (ordinate) to calcium and sodium intakes. See the legend of Figure 1 for details. 

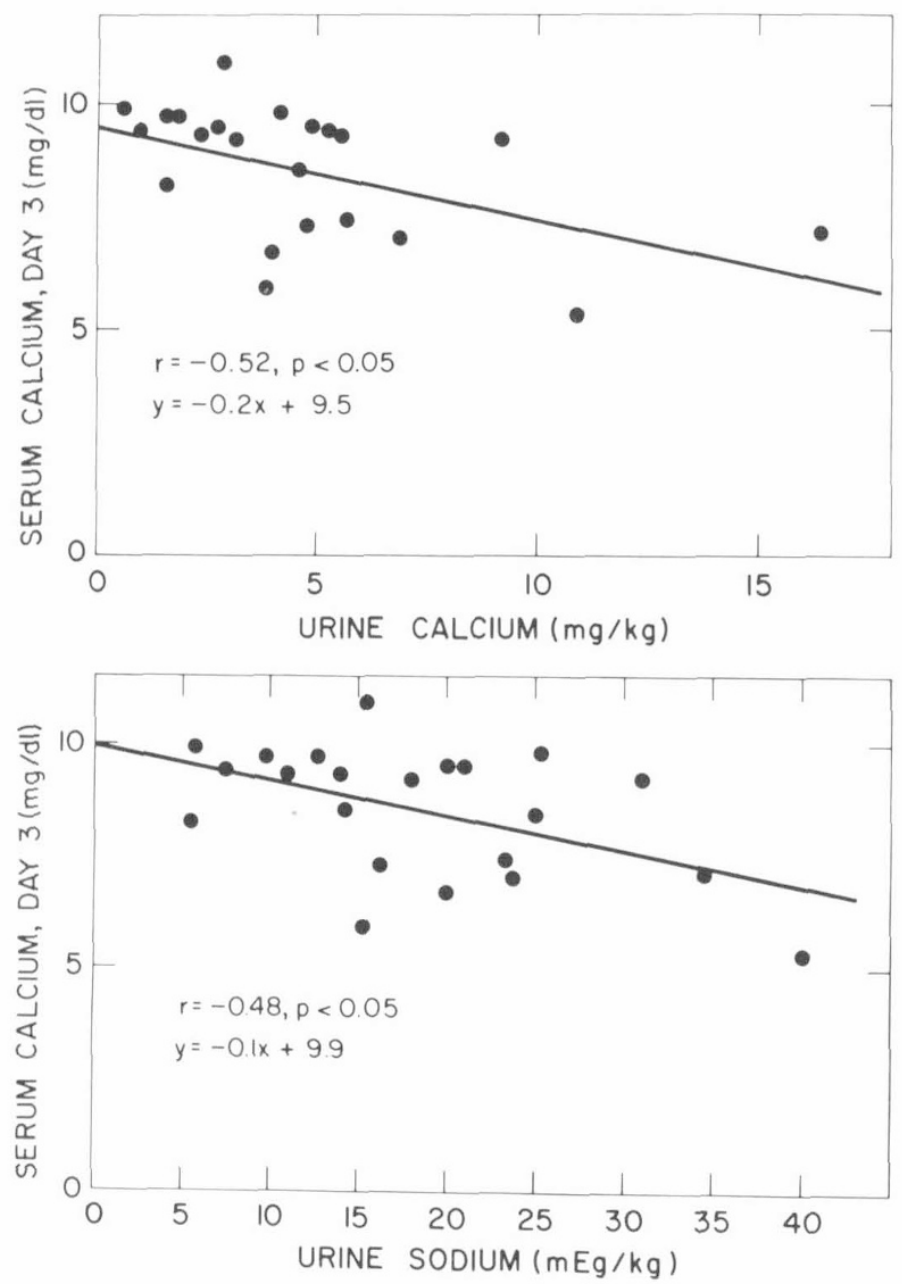

Fig. 5. Correlational relationship of serum calcium concentration at the end of the study to calcium and sodium excretions. See the legend of Figure I for details

\section{DISCUSSION}

This study demonstrates that the excretions of sodium, calcium, and magnesium are strongly interrelated in the hypocalcemic premature human neonate as they are in the adult human (15). Earlier studies of renal function in the neonate suggested that the premature human neonatal kidney wastes sodium $(7,17)$ and that this tendency can be aggravated by increased fluid intake (14). Our patients, who had more medical problems than these previously studied neonates, showed an even greater tendency to waste sodium. More than $70 \%$ (16 of 22; see Fig. 3) of our sick, hypocalcemic, premature patients excreted more sodium than they took in, and our entire study population had a mean tubular reabsorption of sodium of only $95 \%$. The lack of correlation between fluid intake and sodium excretion does not support earlier findings, but it should not be expected to because the fluid intake in our patients was dictated by weight change, and the range over which it varied was not as broad as it would have been were we specifically studying the effect of fluid intake on sodium excretion.

From the results of this study, we suggest that cation excretion is probably controlled by a combination of sodium intake and the intrinsic renal sodium-wasting tendency of the premature neonate and that cation excretion is unrelated to calcium intake and fluid intake in the range experienced by these patients. The relative lack of influence of calcium intake on calcium or magnesium excretion is compatible with results in adults $(8,9)$. In addition, this finding may result from the fact that the premature neonate has a relatively high avidity for calcium, having just come from the intrauterine environment where he had to process and store an exceedingly large calcium intake (20). By contrast, sodium accretion in utero is only about $1 \mathrm{mEq} / \mathrm{kg} /$ day $(20)$, and extrauterine intake may easily exceed requirements. The expected increase in excretion in response to increased intake occurs with sodium.

The clinical importance of these results for the sick premature neonate in the first wk of life lies in their potential relationship to the problem of early onset neonatal hypocalcemia. Sodium excretion can be increased by an increased sodium intake $(1,2)$ which would occur with bicarbonate treatment of acidosis and also with the injection of sodium chloride through arterial catheters. Sodium excretion is also increased by the immature tubular function of these patients, and their immature tubular function can result in primary renal sodium wasting. As shown by our results, sodium excretion implies calcium excretion and may be an important factor controlling calcium excretion. Sodium intake, sodium excretion, and calcium excretion were all negatively related to serum calcium concentration after the three days of our study. It is thus possible that excessive sodium administration not dictated by basal sodium requirements or by hyponatremia, either by itself or by increasing the already present tendency to waste sodium, could aggravate early neonatal hypocalcemia.

The results of the present study are compatible with those of earlier studies showing the tendency of the premature human neonate to waste sodium. In addition, the results show the strong interrelationship among the excretions of sodium, calcium, and magnesium and the weaker relationship of phosphorus excretion to the excretion of these three cations. It also appears that sodium intake in the range that can be seen in clinical practice can influence the excretion of calcium and sodium whereas calcium intake is unrelated to cation excretion. The results also suggest that aggressive administration of sodium in sick, hypocalcemic premature neonates may aggravate early onset neonatal hypocalcemia. Proof of this hypothesis will require further testing in a clinical trial in which intakes of sodium and calcium are studied concurrently and varied independently in this high-risk patient population.

\section{REFERENCES AND NOTES}

1. Aperia. A.. Broberger. O.. Herin, P.. Thodenius, K., and Zetterstrom, R.: A comparative study of the response to an oral $\mathrm{NaCl}$ and $\mathrm{NaHCO}_{3}$ load in newborn preterm and full term infants. Pediatr. Res., 11: 1109 (1977).

2. Aperia. A.. Broberger, O.. Thodenius. K.., and Zetterstrom. R.: Developmental study of the renal response to an oral salt load in preterm infants. Acta Paediatr. Scand.. 63: 517 (1974).

3. Arant. B. S.. Jr.: Developmental patterns of renal functional maturation compared in the human neonate. J. Pediatr., 92: 705 (1978).

4. Ballard. J. L.. Novak. K. K., and Driver, M.: A simplified score for assessment of fetal maturation of newly born infants. J. Pediatr., 95: 769 (1979).

5. Brown. D. R.. Steranka. B. H.. and Taylor, F. H.: Treatment of early-onset neonatal hypocalcemia: Effects on serum calcium and ionized calcium. Am. J. Dis. Child.. 135: 24 (1981).

6. Day. G. M., Chance, G. W.. Radde. I. C.. Reilly, B. J., Park. E., and Sheepers. J.: Growth and mineral metabolism in very low birth weight infants. II. Effects of calcium supplementation on growth and divalent cations. Pediatr. Res., 9. 568 (1975)

7. Engelke, S. C., Shah. B. L.. Vasan, U., and Raye, J. R.: Sodium balance in very low-birth-weight infants. J. Pediatr.. 93:837 (1978).

8. Epstein. F. H.: Calcium and the kidney. Am. J. Med., 45: 700 (1968).

9. Goldberg. M.. Agus. Z. S.. Goldfarb. S.: Renal handling of phosphate, calcium. and magnesium. In: B. M. Brenner, and F. C. Rector, Jr.. The Kidney, Vol. I. p. 344 (W. B. Saunders Company, Philadelphia, 1976).

10. Guignard, J. P., Torrado. A., DaCunha, O., Gautier, E.: Glomerular filtration rate in the first three weeks of life. J. Pediatr., 87: 268 (1975).

11. Kingsley, G. R., and Schaffert, R. R.: Direct microdetermination of sodium. potassium, and calcium in a single biological specimen. Anal. Chem., 25: 1738 (1953).

12. Kleeman. C. R., Bohannan. J.. Bernstein. D.. Ling. S., and Maxwell, M. H. Effects of variations in sodium intake on calcium excretion in normal humans. Proc. Soc. Exp. Biol. Med., 115: 29 (1964).

13. Leake. R. D.. Trygstad, C. W.: Glomerular filtration rate during the period of adaptation to extrauterine life. Pediatr. Res., 11: 959 (1977).

14. Leake. R. D.. Zakauddin, S., Trygstad. C. W.. Fu, P.., and Oh. W.: The effects of large volume intravenous fluid infusion on neonatal renal function. J. Pediatr.. 89: 968 (1976).

15. Massry. S. G., and Coburn. J. W.: The hormonal and non-hormonal control of renal excretion of calcium and magnesium. Nephron, 10:66 (1973).

16. Remington, R. D., and Schork. M. A.: Statistics with Applications to Biological 
and Health Sciences. p. 253 (Prentice-Hall, Inc.. Englewood Cliffs. NJ. 1970). 17. Ross. B.. Cowett. R. M.. and Oh. W.: Renal functions of low birth weight infants during the first two months of life. Pediatr. Res.. /1: II62 (1977).

18. Schwartz. H. D.: Serum ionized calcium by electrodes: New technology and methodology. Clin. Chim. Acta. 64: 227 (1975).

19. Schwartz. H. D.: New techniques for ion-selective measurements of ionized calcium in serum after $\mathrm{pH}$ adjustment of aerobically handled sera. Clin. Chem.. 22: 461 (1976).

20. Shaw. J. C. L.: Parenteral nutrition in the management of sick low birth weight infants. Pediatr. Clin. N. Am., 20:333 (1973).

21. Sunderman. F. W.. Jr.. and Carroll. J. E.: Measurements of serum calcium and magnesium by atomic absorption spectrometry. Am. J. Clin. Pathol., 43: 302 (1963).

Copyright (1) 1981 International Pediatric Research Foundation. Inc. $0031-3998 / 81 / 1508-1100 \$ 02.00 / 0$
22. Tsang. R. C.. Light. I. J.. Sutherland. J. M.. and Kleinman. L. 1.: Possible pathogenetic factors in neonatal hypocalcemia of prematurity. J. Pediatr., 82; 423 (1973).

23. The authors thank Dr. I R. Holzman and Dr. P. M. Taylor for critical review of the manuscript and Carleen Whelan for secretarial assistance. We also thank Bonnie Booher and the nursing staff of the Neonatal Intensive Care Unit for invaluable assistance in caring for the patients and collecting the urine specimens.

24. Requests for reprints should be addressed to: David R. Brown, M. D., Department of Pediatrics. Magee-Womens Hospital. Forbes Avenue and Halket Street. Pittsburgh. PA 15213 (USA).

25. Received for publication June 6. 1980

26. Accepted for publication December 9. 1980 